\title{
Front-Line Service Role Engagement and Subjective Well-Being of Socially Disadvantaged Employees: An Abstract
}

\author{
Darren Garvey, Piyush Sharma, and Russel P. J. Kingshott
}

\begin{abstract}
Indigenous populations in advanced economies such as Australia, Canada, New Zealand and the USA are severely disadvantaged in comparison to the members of the wider society in terms of most socioeconomic, health and wellbeing indicators (e.g. Closing the Gap Report by the Commonwealth Government of Australia, 2017). We address this important sociological challenge facing Australian people, businesses and policy-makers by exploring three specific research questions: (1) does racism directed towards indigenous people still exist within the Australian workplace settings; (2) are some employment types more susceptible to such activity than others, such as front-line service roles; and (3) does employment in specific work settings make indigenous people more resilient to racism than others? Answers to these questions could provide the clue to policy and industry actions designed to improve indigenous well-being and overall life satisfaction and in turn help to remedy injustices of the past that are still omnipresent today (Mellor 2004). In this paper, we begin by briefly reviewing the relevant literature on indigenous employment issues and well-established service management concepts, to develop our conceptual framework with testable propositions and also propose a methodology to test these. We also discuss the conceptual contribution and managerial implications of this research.
\end{abstract}

D. Garvey $\cdot$ P. Sharma $(\bowtie) \cdot$ R. P. J. Kingshott

Curtin University, Bentley, Australia

e-mail: d.garvey@gunada.curtin.edu.au; piyush.sharma@curtin.edu.au;

r.kingshott@curtin.edu.au 